\title{
Characterization and sequence of PhoC, the principal phosphate-irrepressible acid phosphatase of Morganella morganii
}

\author{
Maria Cristina Thaller, ${ }^{1}$ Francesca Berlutti, ${ }^{1}$ Serena Schippa, ${ }^{1}$ \\ Giovanna Lombardi ${ }^{2}$ and Gian Maria Rossolini ${ }^{2}$
}

Author for correspondence: G. M. Rossolini. Tel: +39577 280903. Fax: +3957742011.

1 Istituto di Microbiologia, Università 'La Sapienza', Piazzale A. Moro, 5 , 00185 - Rome, Italy

2 Dipartimento di Biologia Molecolare - Sezione di Microbiologia, Università di Siena, Via Laterina, 8 , 53100 - Siena, Italy

\begin{abstract}
Phosphatase activities were investigated in Morganella morganii, which is one of the few enterobacterial species producing high-level phosphateirrepressible acid phosphatase activity (HPAP phenotype), and the gene encoding the major phosphate-irrepressible acid phosphatase was cloned, sequenced, and its product characterized. Using p-nitrophenyl phosphate as substrate, Morganella produced a major phosphate-irrepressible acid phosphatase (named PhoC) which is associated with the HPAP phenotype, a minor phosphate-irrepressible acid phosphatase, and a phosphate-repressible alkaline phosphatase. The presence of the PhoC activity prevented induction of alkaline phosphatase when a PhoC-hydrolysable organic phosphate ester, such as glycerol 2-phosphate, was the sole phosphate source. PhoC is a secreted nonspecific acid phosphatase apparently composed of four $25 \mathrm{kDa}$ polypeptide subunits. The enzyme is resistant to EDTA, $P_{i}$, fluoride and tartrate. The $M$. morganii PhoC showed $84.6 \%$ amino acid sequence identity to the PhoN nonspecific acid phosphatase of Providencia stuartii, 45.3\% to the PhoN nonspecific acid phosphatase of Salmonella typhimurium, and $37.8 \%$ to the principal acid phosphatase (PhoC) of Zymomonas mobilis. Comparison of sequence data and of regulation of these enzymes suggested a different phylogeny of members of this gene family within the Enterobacteriaceae.
\end{abstract}

Keywords: Morganella morganii, PhoC, phosphatase activities

\section{INTRODUCTION}

In members of the family Enterobacteriaceae, production of phosphatase activity is a constant feature (Cocks \& Wilson, 1972; Satta et al., 1988), but different enzymic patterns have been observed in different species (Cocks \& Wilson, 1972; Pompei et al., 1990, 1993). Such differences have been confirmed at the molecular level in the case of Escherichia coli and Salmonella typhimurium, which are the best characterized enterobacterial species from this point of view. In fact, although some activities are present in both species, such as $2^{\prime}, 3^{\prime}$-cyclic phosphodiesterases and acid hexose phosphatases (Dvorak et al., 1967; Kier et al., 1977a), S. typhimurium is apparently lacking a counterpart for the alkaline phosphatase and periplasmic UDP-sugar

Abbreviations: G2P, glycerol 2-phosphate; HPAP, high-level phosphateirrepressible production of acid phosphatase activity; pNPP, $p$-nitrophenyl phosphate.

The GenBank accession number for the sequence data reported in this paper is X64444. hydrolase found in E. coli (Cocks \& Wilson, 1972; Neu, 1968; Schlesinger \& Olsen, 1968), while E. coli is apparently lacking a counterpart for the PhoN nonspecific acid phosphatase found in S. typhimurium (Kasahara et al., 1991). Differences between these species could also extend to other acid phosphatases, but the limited information concerning properties of a nonspecific acid phosphatase fraction described in E. coli (Dvorak et al., 1967), and the lack of information on the possible presence in $S$. typhimurium of an enzyme active at very low $\mathrm{pH}$ values similar to the E. coli AppA enzyme (Dassa et al., 1982), do not allow a precise comparison in this case.

Since they show diverse patterns of expression, characterization of the different phosphatases that have evolved in the Enterobacteriaceae could provide a relevant contribution, not only to the knowledge of the physiology and evolution of these enzymes and of their regulation, which is still limited, but also to evolutionary studies in the enterobacterial genome (see for instance Groisman $e t$ al., 1992). 
Among the various patterns of phosphatase activity observed in Enterobacteriaceae, a peculiar one consists in a high-level phosphate-irrepressible production of acid phosphatase activity (HPAP phenotype), which has thus far been observed in Morganella morganii and Providencia stuartii (Pompei et al., 1990, 1993). For this reason, we have started to investigate the phosphatases of the above species.

In this report we have studied in some detail the phosphatases of $M$. morganii (as a representative HPAP ${ }^{+}$ species) and found some differences in their pattern as compared to that of other Enterobacteriaceae.

M. morganii is an enterobacterial species occurring in low frequency in the intestines of mammals and some reptiles (Phillips, 1955; Winslow et al., 1919) and, recently, the calf intestine has been reported as a major source of this species (Hawkey et al., 1986). In humans, Morganella can be responsible for urinary tract infections as a primary pathogen, and can also occur as an opportunistic secondary invader in infections of various parts of the body (von Graevenitz \& Spector, 1969; Williams et al., 1983).

\section{METHODS}

Culture media and conditions. To study phosphatase activities produced by $M$. morganii under different conditions of $\mathrm{P}_{1}$ availability, SP medium (devised on the basis of preliminary experiments) was used. Composition (in $\mathrm{g}^{-1}$ ) of the SP medium was as follows: $\mathrm{NaCl}, 0.5 ; \mathrm{KCl}, 0.4 ; \mathrm{MgSO}_{4} .7 \mathrm{H}_{2} \mathrm{O}, 0.2$; $\mathrm{CaCl}_{2} .2 \mathrm{H}_{2} \mathrm{O}, 0.265 ; \mathrm{NH}_{4} \mathrm{Cl}, 0.535$; glucose, 4; L-arginine, 0.126 ; L-cysteine, 0.012 ; L-glutamine, 0.292 ; L-histidine, 0.042 ; L-isoleucine, 0.052; L-leucine, 0.052; L-lysine, 0.0725; L-methionine, 0.05 ; L-phenylalanine, 0.0325; L-threonine, 0.048 ; Ltryptophan, 0.01 ; L-tyrosine, 0.036 ; L-valine, 0.046 ; biotin, 0.001 ; folic acid, 0.001 ; nicotinic acid, 0.001 ; pantothenic acid, 0.001 ; pyridoxal, 0.001 ; riboflavin, 0.0001 ; thiamin, 0.001 . The medium was buffered with $200 \mathrm{mM}$ Tris $/ \mathrm{HCl}, \mathrm{pH} 7 \cdot 2$. Phosphate sources $\left(P_{i}\right.$ or $\left.G 2 P\right)$ were added to the desired final concentration.

For studying production of phosphatase activities under different conditions of $P_{1}$ availability, bacteria exponentially growing in SP medium containing $1 \mathrm{mM} \mathrm{P} \mathrm{P}_{1}$ were washed in sterile saline (at $37^{\circ} \mathrm{C}$ ) and inoculated in prewarmed SP medium containing $1 \mathrm{mM} \mathrm{P}, 1 \mathrm{mM} \mathrm{G} 2 \mathrm{P}$, or $0.005 \mathrm{mM} \mathrm{P}$. Bacteria grown in the above assay media were then collected at the mid exponential phase of growth. In the SP medium containing $0.005 \mathrm{mM} \mathrm{P}_{1}$ bacterial growth was limited to only a few generations and in this case cells were always collected after a $5 \mathrm{~h}$ incubation time.

All strains were grown aerobically at $37^{\circ} \mathrm{C}$.

Bacterial strains and genetic vectors. The $M$. morganii strains used in this study were from the strain collection at the Institute of Microbiology, University 'La Sapienza', Rome, and had been identified according to standard procedures (Farmer \& Kelly, 1991). All strains were clinical isolates from humans with urinary tract infections.

E. coli DH5 $\alpha$ (Sambrook et al., 1989) was used as the host for genetic vectors and recombinant plasmids.

The Bluescript SK plasmid (Stratagene) was used for the construction of the $M$. morganii RS12 genomic library and for subcloning procedures.
Phosphatase assays. The phosphatase activity of whole cell or periplasmic protein preparations toward $p$-nitrophenyl phosphate ( $p$ NPP) was assayed by measuring the released $p$ nitrophenol at $414.5 \mathrm{~nm}$ at $\mathrm{pH} 12$. The concentration of $p \mathrm{NPP}$ in the assay was $5 \mathrm{mM}$. All assays were performed in a volume of $1 \mathrm{ml}$ and were initiated by addition of the substrate. Incubation was at $37^{\circ} \mathrm{C}$ for $20 \mathrm{~min}$. One unit of enzyme activity was defined as the amount of enzyme able to release $1 \mathrm{nmol}$ of $p$-nitrophenol per min under the assay conditions. The assays were performed in $100 \mathrm{mM}$ buffers, including sodium acetate buffer ( $\mathrm{pH} 5$ and 6), Tris/ $\mathrm{HCl}$ buffer $(\mathrm{pH} 7-9$ ), and glycine/ $\mathrm{NaOH}$ buffer ( $\mathrm{pH} 10$ ). Measurement of enzymic activity in different buffer systems at overlapping $\mathrm{pH}$ values showed no significant buffer-related variation.

For preparation of whole-cell proteins, bacteria were washed twice in normal saline, resuspended in normal saline at an $A_{590}$ of $\simeq 10$, and disrupted by sonication. Cell debris was then removed by centrifugation $\left(10000 \mathrm{~g}\right.$ for $10 \mathrm{~min}$ at $\left.4{ }^{\circ} \mathrm{C}\right)$. Extraction of periplasmic proteins from E. coli was performed by chloroform treatment (Ferro-Luzzi Ames et al., 1984).

Determination of the activity of the purified $\mathrm{PhoC}$ protein using different substrates was performed as previously described (Kier et al., 1977a; Weppelman et al., 1977) in $100 \mathrm{mM}$ sodium acetate buffer, $\mathrm{pH}$ 6. Inhibition assays were performed in the same buffer using $p$ NPP as the substrate. The enzyme was preincubated at $37^{\circ} \mathrm{C}$ for $30 \mathrm{~min}$ with each substance before starting the assay.

Protein determination. Protein concentration in solution was determined using a commercial kit (Bio-Rad protein assay). BSA was used as the standard.

Protein electrophoretic techniques. SDS-PAGE was performed as previously described (Laemmli, 1970). After electrophoresis the gels were either stained with Coomassie brilliant blue R250 or incubated for $4 \mathrm{~h}$ at $37^{\circ} \mathrm{C}$ in several changes of renaturation buffer to obtain renaturation of enzymes. Renaturation buffer was $100 \mathrm{mM}$ Tris $/ \mathrm{HCl}, \mathrm{pH} 7$, containing $5 \mathrm{mM} \mathrm{MgSO}_{4}$ and $1 \%(\mathrm{v} / \mathrm{v})$ Triton $\mathrm{X}-100$. After the renaturation treatment, gels were equilibrated for $1 \mathrm{~h}$ in either $100 \mathrm{mM}$ sodium acetate buffer, $\mathrm{pH} 6$, or $100 \mathrm{mM}$ glycine/ $\mathrm{NaOH}$ buffer, $\mathrm{pH} 10$, both containing $5 \mathrm{mM} \mathrm{MgSO}_{4}$, and then developed for phosphatase activity. For development, the gel was incubated at $37^{\circ} \mathrm{C}$ for $30 \mathrm{~min}$ in the same buffer used for equilibration with $5 \mathrm{mM} p \mathrm{NPP}$ added, washed in deionized water, and then incubated at $42^{\circ} \mathrm{C}$ in a freshly prepared solution made by a $6: 1(\mathrm{v} / \mathrm{v})$ mixture of acidified ammonium molybdate ( $4.2 \mathrm{~g}$ ammonium molybdate $\mathrm{l}^{-1}$ and $28.6 \mathrm{ml}$ sulphuric acid $^{-1}$ ) and $10 \%(\mathrm{w} / \mathrm{v})$ ascorbic acid, to detect the presence of $\mathrm{P}_{i}$ (Ames, 1966). Phosphatase activities were indicated by the presence of blue-stained bands.

Purification of the PhoC enzyme. When E. coli strains producing the Morganella $\mathrm{PhoC}$ enzyme were grown in liquid medium at $37^{\circ} \mathrm{C}$, a consistent amount of the protein was released in the culture medium. The PhoC protein present in the medium of 24-h-old stationary phase cultures in Brain Heart Infusion broth supplemented with carbenicillin $\left(0.2 \mathrm{mg} \mathrm{ml}^{-1}\right)$ represented approximately $50 \%$ of the total proteins present in the medium, as evaluated by a densitometric scan of a Coomassie-blue-stained polyacrylamide gel (data not shown); its estimated amount was approximately $0.1 \mathrm{mg} \mathrm{ml}^{-1}$. A similar culture supernatant was dialysed against $10 \mathrm{mM}$ sodium acetate buffer, pH 6 (buffer A), until complete removal of $\mathrm{P}_{\mathrm{i}}$, and then used as the starting material for purification of the PhoC protein. For phosphocellulose chromatography, the dialysed supernatant was washed onto a phosphocellulose (Whatman P11) column (Poly-Prep chromatography column; Bio-Rad) 
previously equilibrated with buffer $\mathrm{A}$. The PhoC enzyme was then eluted with $20 \mathrm{mM}$ sodium phosphate buffer, $\mathrm{pH} 6$.

For determination of the molecular mass of the $\mathrm{PhoC}$ protein by means of gel filtration, the culture supernatant or the purified protein was applied to a Sephacryl S-200 column $(1 \times 20 \mathrm{~cm})$ equilibrated and eluted with buffer A. The Sephacryl S-200 column was calibrated with protein standards dissolved in elution buffer. The peak fraction of each protein was determined by measuring the $A_{\mathbf{2 8 0}}$. A linear plot of the partition coefficients (Reiland, 1971) versus the logs of the molecular masses of the protein standards was used to estimate the molecular mass of the phosphatase.

Amino-terminal amino acid sequencing. The purified protein preparation was subjected to SDS-PAGE and transferred electrophoretically to a polyvinylidene difluoride membrane (Immobilon, Millipore). The transferred protein was stained with Coomassie brilliant blue R-250, and the band was excised and subjected to sequence analysis using an Applied Biosystems model 470A gas-phase sequencer (Matsudaira, 1987).

Recombinant DNA methodology. Basic recombinant DNA techniques were essentially as described by Sambrook et al. (1989). High molecular mass chromosomal DNA was extracted from $M$. morganii as described by Frankel et al. (1989), with the addition of a phenol deproteinization step. For construction of the Morganella genomic library, chromosomal DNA was partially digested with SauBAI restriction endonuclease to obtain restriction fragments more abundantly represented in the range from 1 to $10 \mathrm{~kb}$; following removal of the smaller DNA fragments by PEG precipitation (Lis, 1980), the restriction fragments were ligated to BamHI-linearized and dephosphorylated plasmid Bluescript SK. Unidirectional deletions of DNA fragments using exonuclease III and nuclease S1 were performed as previously described (Henikoff, 1984). All sequences were determined on denatured double-stranded DNA templates by the dideoxy-chain termination method (Sanger et al., 1977). The nucleotide sequence was determined for both strands. Comparison and alignment of sequences was performed using the Clustal program (Higgins \& Sharp, 1988). The minimum value for conservative amino acid substitutions according to the log-odds matrix of Dayhoff was fixed at 8.

\section{RESULTS AND DISCUSSION}

\section{Analysis of phosphatase activities in $M$. morganii under conditions of different $P_{i}$ availability}

As previously mentioned, $M$. morganii is one of the enterobacterial species showing an $\mathrm{HPAP}^{+}$phenotype (Pompei et al., 1990, 1993). However, Morganella strains are occasionally found which apparently lack this phenotype (Thaller et al., 1992a). To characterize the phosphatase activities produced by $M$. morganii under conditions of different $\mathrm{P}_{\mathrm{i}}$ availability, two $\mathrm{HPAP}^{+}$strains (RS12 and RS24) and one HPAP ${ }^{-}$strain (RS31) were selected.

Using $p$ NPP as substrate, phosphatase activity produced by the above strains was analysed, at different $\mathrm{pH}$ values, in whole cell protein preparations obtained from cultures growing in media of different composition. The HPAP ${ }^{+}$ strains RS12 and RS24 showed high-level production of phosphatase activity under all growth conditions. Activity peaked at acidic $\mathrm{pH}$ value when cells were grown in SP medium either containing abundant $P_{i}(1 \mathrm{mM})$ or G2P
$(1 \mathrm{mM})$ as the sole phosphate source, the activity pattern being similar in both conditions (Fig. 1a). In $\mathrm{P}_{\mathrm{i}}$-starved cultures with no addition of any organic phosphate source (SP medium containing $0.005 \mathrm{mM} \mathrm{P}_{\mathrm{i}}$ ) high-level phosphatase activity at acidic $\mathrm{pH}$ values was still present, but a peak of phosphatase activity appeared at alkaline $\mathrm{pH}$

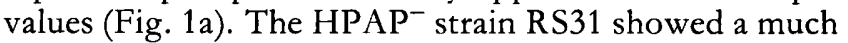
lower phosphatase activity, as compared to that of the two $\mathrm{HPAP}^{+}$strains, when cells were grown in the SP medium containing abundant $P_{i}$. In this strain, growth on G2P as the sole phosphate source caused a moderate increase of phosphatase activity, peaking at alkaline $\mathrm{pH}$ values, while $\mathrm{P}_{\mathrm{i}}$-starvation with no available organic phosphate source caused a remarkable increase of phosphatase activity, peaking at alkaline $\mathrm{pH}$ values (Fig. $1 \mathrm{~b}$ ).

To analyse in more detail the phosphatase activities produced by $M$. morganii under the above culture conditions, zymograms were performed on whole cell protein preparations obtained from cultures grown under different conditions, using $p$ NPP as the substrate. This analysis showed that, in $\mathrm{HPAP}^{+}$Morganella strains, a major and a minor acid phosphatase activity, constituted by 25 and $27 \mathrm{kDa}$ polypeptide units, respectively, were produced under any culture conditions, while an alkaline phosphatase activity, constituted by a $48 \mathrm{kDa}$ polypeptide unit, was produced only when cells were grown under conditions of absolute $\mathrm{P}_{\mathrm{i}}$-deprivation. The major acid phosphatase, named PhoC, retained part of its activity also at alkaline $\mathrm{pH}$ values, and its production was apparently somewhat reduced when cells were $P_{\mathrm{i}}$-starved and alkaline phosphatase was also produced (Fig. 2). In the $\mathrm{HPAP}^{-}$strain, the dominant feature was represented by a complete lack of production of the PhoC enzyme under any culture conditions, while the minor acid phosphatase activity was still produced. Expression of alkaline phosphatase appeared to be $\mathrm{P}_{\mathrm{i}}$-regulated, as in the $\mathrm{HPAP}^{-}$strains. In this case, however, alkaline phosphatase was also produced when G2P was the sole phosphate source, although in a lower amount compared to that observed in $\mathrm{P}_{\mathrm{i}}$-starved cultures (data not shown).

The data from zymograms were consistent with those obtained from the measurement of total enzymic activity and indicated that at least two $\mathrm{P}_{\mathrm{i}}$-irrepressible acid phosphatases, constituted by low molecular mass polypeptide chains, are produced by $M$. morganii and may contribute to the $\mathrm{HPAP}^{+}$phenotype typical of this species. Of the two enzymes, PhoC is likely to be necessary for, as well as the principal (if not the only) enzyme responsible for, this phenotype, since it was by far the major activity and was lacking in the RS31 $\mathrm{HPAP}^{-}$strain. Confirmation of these assumptions will be achieved by the construction and analysis of isogenic mutants for the genes encoding each enzyme.

Under conditions of low- $\mathrm{P}_{\mathrm{i}}$ availability, as previously reported (Cocks \& Wilson, 1972), Morganella is also able to produce an alkaline phosphatase which, according to its regulation and the molecular mass of its polypeptide component, is probably similar to that of E. coli (Bradshaw et al., 1981; Garen \& Levinthal, 1960; Torriani, 1960). The fact that in Morganella, unlike in E. coli (Torriani, 

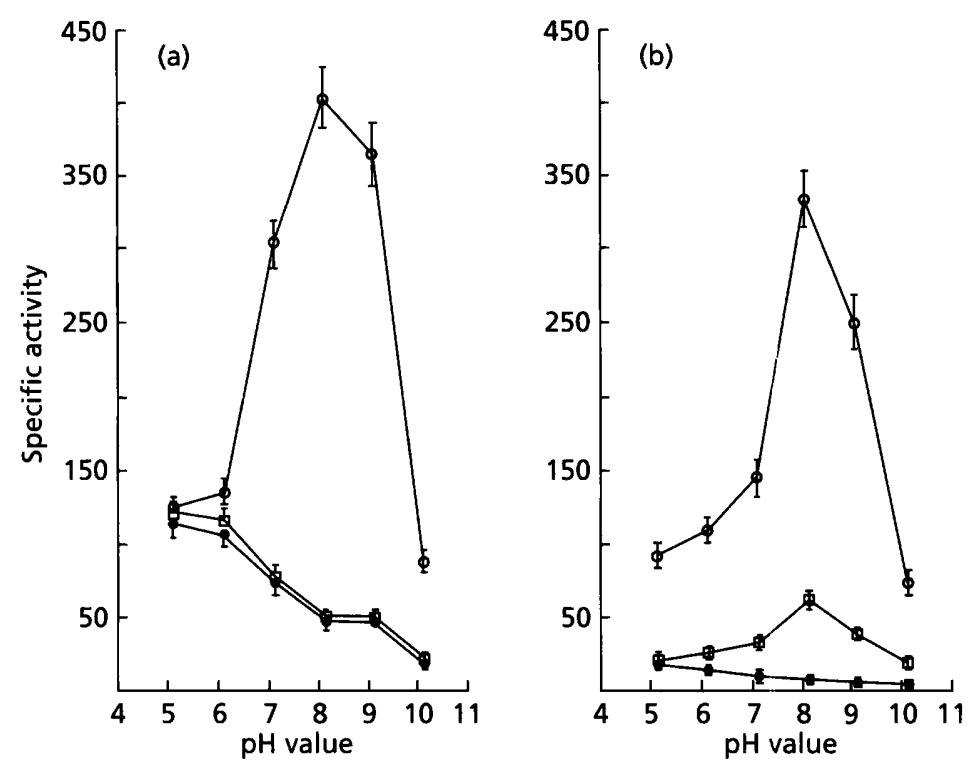

Fig. 1. Total phosphatase activity against $p N P P$, at different $\mathrm{pH}$ values, of (a) $M$. morganii RS12 and (b) $M$. morganii RS31. The assay was performed using whole cell protein preparations from cultures growing in media of different composition. $\mathrm{SP}$ medium $+1 \mathrm{mM} \mathrm{P}_{\mathrm{i}} ; \square$, SP medium $+1 \mathrm{mM}$ G2P; O, SP medium $+0.005 \mathrm{mM} \mathrm{P}$. The values are reported in $U$ (mg total protein) ${ }^{-1}$ and represent mean values of three different experiments (standard error bars are also shown; for points closely spaced with other points, only the upper or the lower half of the bar is shown). The activity profiles observed were reproducible in the three experiments. Results obtained with strain RS24 were the same as those obtained with strain RS12, and are not shown.

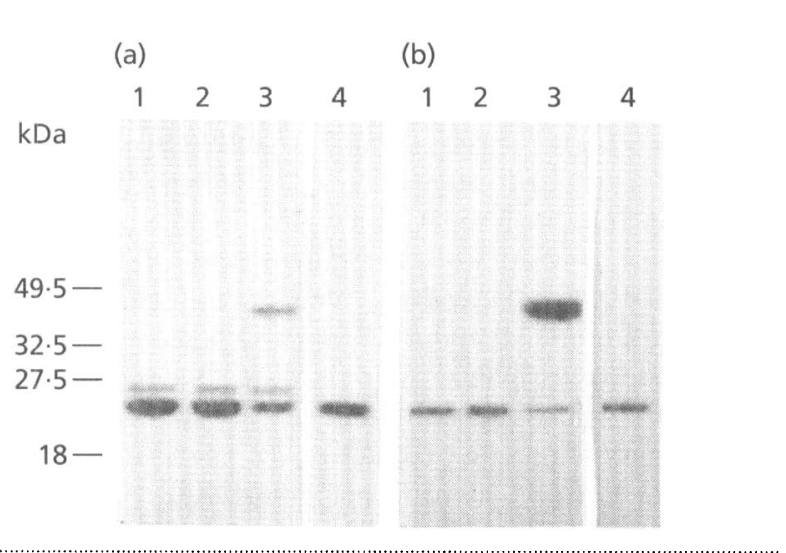

Fig. 2. Zymograms developed for phosphatase activity at $\mathrm{pH} 6$ (a) or 10 (b) after renaturing SDS-PAGE. Lanes: 1-3, whole-cell proteins (approximately $0.1 \mathrm{mg}$ ) from strain RS12 growing in SP medium $+1 \mathrm{mM} \mathrm{P}_{\mathrm{i}}, \mathrm{SP}$ medium $+1 \mathrm{mMG} 2 \mathrm{P}$ and $\mathrm{SP}$ medium $+0.005 \mathrm{mM} \mathrm{P}_{i}$, respectively; 4, periplasmic proteins from the PM11 E. coli clone. Protein size markers are reported in $\mathrm{kDa}$ on the left. These zymogram patterns were reproducible in triplicate experiments and representative results are shown. Results obtained with strain RS24 were the same as those obtained with RS12, and are not shown.

1960), production of alkaline phosphatase remains fully repressed when an organic phosphate ester such as G2P becomes the sole phosphate source, is likely to be due to the presence of the two phosphate-irrepressible acid phosphatases, both of which are able to hydrolyse G2P (see below, and M. C. Thaller and others, unpublished) and, in doing so, would provide enough $\mathrm{P}_{\mathrm{i}}$ to prevent induction of alkaline phosphatase. A relevant role of PhoC in this phenomenon is suggested by the fact that, in the HPAP ${ }^{-}$RS31 strain which does not produce PhoC, alkaline phosphatase is actually produced when G2P is the only phosphate source.

The zymogram technique appeared to be very useful for a rapid and rather comprehensive analysis of the phos-

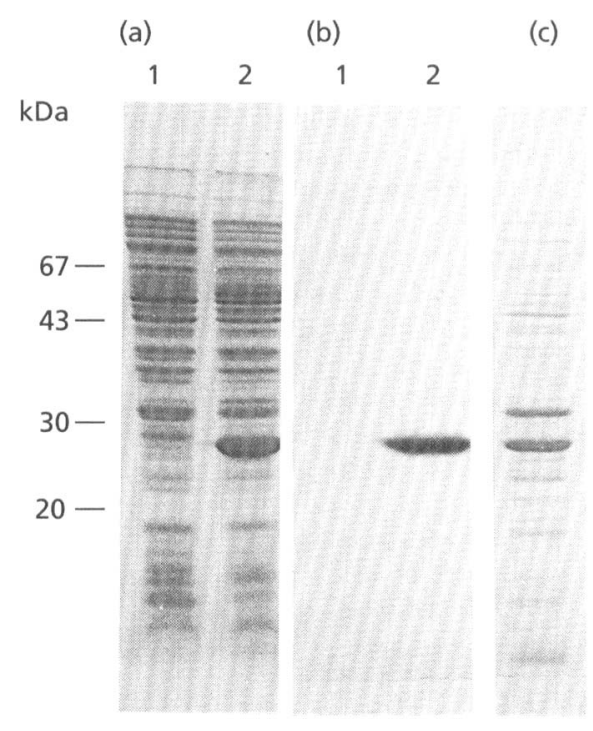

Fig. 3. SDS-PAGE analysis of proteins of the PM11 clone. (a) Coomassie-blue-stained whole cell protein preparations of $E$. coli DH5 $\alpha$ (pBluescript) (lane 1) and PM11 (lane 2). (b) Same samples as in (a) but in this case a lower amount of protein was loaded and, after electrophoresis, the gel was subjected to renaturation treatment and developed for phosphatase activity against pNPP at pH 6. (c) Coomassie-blue-stained periplasmic proteins of PM11. Protein size markers are reported in $\mathrm{kDa}$ on the left.

phatase activities produced under different growth conditions. The study of bacterial phosphatases, in fact, is complicated by the fact that many such enzymes are produced in the cell and their production can be regulated by multiple mechanisms. Therefore, the classical approach of selection of mutants altered in production of a given phosphatase may be hampered by the presence of other overlapping activities, while the classical procedure of purification and characterization of different enzymic 


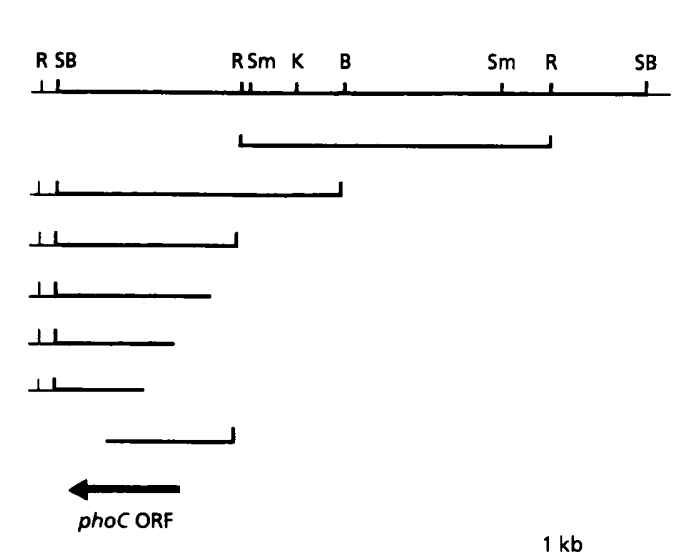

Clone

pPM11

PPM20R

PPM18BR

PPM12R

pPM12R $\Delta R(-193)$

pPM12R $\Delta R(+136)$

PPM12R $\Delta R(+261)$

PPM12R $\Delta L(+487)$
Fig. 4. Restriction endonuclease map of the DNA insert of the recombinant plasmid carried by PM11, subcloning strategy, and deletion analysis. Abbreviations: B, BamHI; R, EcoRl; K, Kpnl; SB, Sau3Al/BamHI junction; Sm, Smal. Thick lines represent Morganella DNA, while thin lines represent vector sequences. The location of the putative PhoC ORF, identified on the basis of sequencing data and deletion analysis, is shown below the map. Production of the PhoC protein was assayed both by measuring pNPP-hydrolysing activity at $\mathrm{pH} 6$, and by SDS-PAGE analysis of periplasmic proteins of different subclones. PhoC production by $E$. coli (PPM12R) occurred independently of insert orientation. Deletion derivatives of PPM12R are indicated as $\Delta R$ or $\Delta L$ according to the extremity (right or left, respectively) of the insert from which the deletion process was started. Numbers in parentheses indicate the position of the first undeleted nucleotide according to the numbering reported in Fig. 6. activities can be rendered even more cumbersome by the need of repetition in several different culture conditions. The renaturing SDS-PAGE technique was preferred to native electrophoresis techniques since it allowed a good resolution of activities, providing at the same time information on the molecular mass of the polypeptide which constitutes the protein.

The fact that we were not able to detect other phosphatase activities, such as cyclic phosphodiesterase, 5'-nucleotidase, or hexose-phosphatase, in zymograms should not be surprising since the above experiments were performed using $p$ NPP as substrate (which may not be hydrolysed by some of the above enzymes) and using growth conditions which may not induce some of the above enzymes. Using the same zymogram technique in combination with appropriate culture conditions and substrates, we were actually able to detect putative hexose-phosphatase and phosphodiesterase activities in $M$. morganii (Thaller and others, unpublished). Since Morganella phosphatase activity was not assayed at very low $\mathrm{pH}$ values, the presence of enzymic activities similar to the $E$. coli AppA enzyme (Dassa et al., 1982) could not have been detected. It should finally be noted that the use of a renaturing SDS-PAGE technique could have also resulted in missing enzymic activities which are either heteropolymeric in nature or not able to renature following SDS-PAGE.

\section{Cloning of the $\boldsymbol{M}$. morganii genetic determinant coding for the major phosphate-irrepressible acid phosphatase (PhoC)}

The $M$. morganii gene coding for the major phosphateirrepressible acid phosphatase was isolated by a shotguncloning strategy which allows the isolation of different phosphatase-encoding genes in one step (M. L. Riccio and others, unpublished) using an indicator medium that does not detect $E$. coli phosphatase activity (Satta et al., 1979 , 1988). Briefly, a genomic library of RS12, constructed in the plasmid vector Bluescript SK and transformed in E. coli DH5 $\alpha$, was screened for clones able to grow as green-stained colonies on tryptose-phosphate agar plates containing the phosphatase substrate phenolphthalein diphosphate $\left(2 \mathrm{mg} \mathrm{ml}^{-1}\right)$, methyl green $\left(0.05 \mathrm{mg} \mathrm{ml}^{-1}\right)$ and carbenicillin $\left(0.1 \mathrm{mg} \mathrm{ml}^{-1}\right)$ for plasmid selection.

A green-stained clone (PM11) was thus identified, which showed a much higher acid phosphatase activity than $E$. coli DH5 $\alpha$ (pBluescript) (data not shown) and produced a $25 \mathrm{kDa}$ polypeptide, not present in E. coli (Fig. 3a), endowed with phosphatase activity at acidic $\mathrm{pH}$ after allowing in-gel renaturation of proteins (Fig. $3 \mathrm{~b}$ ). Comparison of the acid phosphatase produced by the PM11 clone to the Morganella phosphatases resolved by the zymogram technique showed that it apparently corresponded to the PhoC acid phosphatase (Fig. 2). The acid phosphatase produced by the PM11 clone could be extracted by a chloroform treatment suitable for extraction of the periplasmic proteins from E. coli (FerroLuzzi Ames et al., 1984) (Fig. 3c), and the ratio of phosphatase activity between a periplasmic and a whole cell protein preparation from this clone was consistent with a location of this protein into the periplasmic space.

The cloned DNA fragment harboured by the PM11 clone was mapped (Fig. 4), and its origin was confirmed by digestion of chromosomal DNA of $M$. morganii RS12 with several restriction endonucleases and analysis of restriction fragments by Southern blotting, using the cloned fragment as the hybridization probe (data not shown).

The above results suggested that the Morganella gene encoding the major phosphate-irrepressible acid phosphatase had been cloned. Definitive confirmation that the enzyme produced by the PM11 clone was actually encoded 


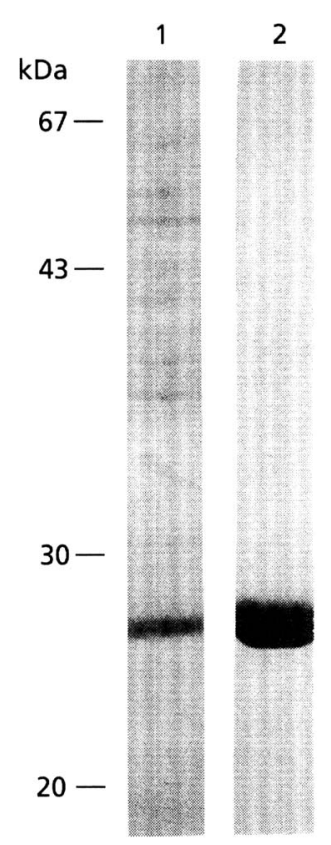

Fig. 5. SDS-PAGE analysis of the purified PhoC protein. Lanes: 1 , culture supernatant $(0.08 \mathrm{ml})$ of the PM11 E. coli clone which was used as the starting material for purification; 2, purified PhoC protein (approximately $0.08 \mathrm{mg}$ ).

Table 1. Relative activities of the PhoC enzyme toward various substrates

\begin{tabular}{|lc|}
\hline Substrate & Relative activity \\
\hline $5^{\prime}$-UMP & $1 \cdot 00$ \\
$5^{\prime}$-AMP & $1 \cdot 17$ \\
$3^{\prime}$-UMP & 0.07 \\
$3^{\prime}$-AMP & 0.05 \\
NPP & $2 \cdot 45$ \\
Phenolphthalein diphosphate & 1.51 \\
G2P & 0.19 \\
Glucose 6-phosphate & 1.44 \\
bis- $p$ NPP & $<0.01$ \\
$2^{\prime}: 3^{\prime}$-cyclic UMP & $<0.01$ \\
$2^{\prime}: 3^{\prime}$-cyclic AMP & $<0.01$ \\
\hline
\end{tabular}

by the cloned Morganella fragment was obtained by comparison of amino-terminal sequencing data of the enzyme to the nucleotide sequence of the cloned insert (see below).

\section{Characterization of the PhoC enzyme}

Purification of the Morganella PhoC enzyme produced by the E. coli PM11 clone was obtained in a single step using phosphocellulose column chromatography (Fig. 5; see Methods for details on the purification procedure). The specific activity of the purified protein, assayed against $p \mathrm{NPP}$ at $\mathrm{pH} 6$, was $7487 \mathrm{U} \mathrm{mg}^{-1}$.
The amino-terminal sequence of the PhoC protein was determined as $\mathrm{NH}_{2}$-AIPAGNDATTKPDLYYLKNE.

The molecular mass of the protein, estimated by gelfiltration chromatography, was approximately $95 \mathrm{kDa}$. This finding was confirmed by ultrafiltration experiments, which showed that the protein was completely retained by filters which excluded globular proteins of sizes larger than $30 \mathrm{kDa}$, while being only partially retained by filters which excluded globular proteins of sizes larger than $100 \mathrm{kDa}$. The above data, along with results of renaturing SDS-PAGE, suggest that the native protein is a homotetramer of the $25 \mathrm{kDa}$ polypeptide.

The purified protein preparation was used to analyse some of its functional properties. Using $p$ NPP as substrate, the PhoC enzyme had a $\mathrm{pH}$ optimum around 6 , retaining part of its activity within a broad $\mathrm{pH}$ range (data not shown; see also Fig. 2). The enzyme showed a broad substrate specificity which did not include diesters (Table 1). The activity of the PhoC enzyme against $p$ NPP was fully retained in the presence of EDTA (up to $20 \mathrm{mM}$ was assayed), fluoride (up to $10 \mathrm{mM}$ was assayed) or tartrate (up to $10 \mathrm{mM}$ was assayed). Enzymic activity was also fully retained in the presence of up to $10 \mathrm{mM} \mathrm{P}$, while a slight inhibition (approximately 10\%) was observed in the presence of $100 \mathrm{mM} \mathrm{P}_{\mathbf{i}}$.

The functional properties of the $\mathrm{PhoC}$ protein are similar overall to those of the PhoN nonspecific acid phosphatase of $S$. typhimurium, the similarity extending also to the size of the polypeptide component (Uerkvitz \& Beck, 1981; Weppelman et al., 1977). Unlike the Salmonella enzyme, however, the Morganella $\mathrm{PhoC}$ protein is apparently more active on $5^{\prime}$-nucleotides than on $3^{\prime}$-nucleotides and is not inhibited by fluoride ions. Moreover, a difference in the quaternary structure of the two enzymes is suggested by the fact that the molecular mass of the Morganella PhoC enzyme is higher (approximately twofold) than that of the Salmonella PhoN protein (Uerkvitz \& Beck, 1981; Weppelman et al., 1977). It should be noted that the two enzymes are also similar at the level of the primary structure (see below), so the functional and quaternary structure differences are likely to be related to discrete differences between the two amino acid sequences. These two enzymes, therefore, could represent a valuable starting model for studies on the structure-function relationship in this class of enzymes.

\section{Structure of the phoC gene}

The $p h o C$ gene was preliminarily located within the $1.2 \mathrm{~kb}$ Sau3AI-EcoRI DNA fragment of the cloned insert by generating different subclones and assaying their ability to produce the PhoC protein (Fig. 4).

The nucleotide sequence of this Morganella DNA fragment was determined (Fig. 6), and computer analysis for possible coding regions identified a single open reading frame (ORF) whose size was compatible with the results of SDS-PAGE analysis, and which was able to code for a polypeptide containing an amino acid sequence corresponding to the amino-terminal sequence of the $\mathrm{PhoC}$ protein (see above). This ORF has the potential to code 


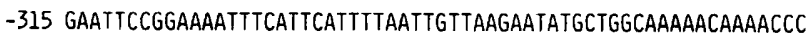

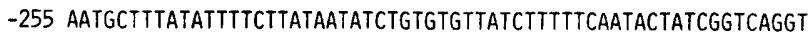
-195 CTTATtTATCCGTtCGITAACAAAAGCCATGCTGtTTCTGtCAAATtATCTGAAAATCAT

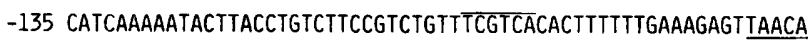
-75 ICAATTTGCATCTCTCCGCCCTACACTGGCAAACAGGTTTCTGAGTAATACTGTTGTATC -15 TGATAAGGAGATGTCATGAAGAAGAATATTATCGCCGGTTGTCTGTTCTCACTGTTTTCC $M \quad K \quad K \quad N$ I I A A G C L F

+46 CTTTCCGCACTGGCCGCGATCCCGGCAGGCAACGATGCCACCACCAAGCCGGATTTATAT $L$ S A L $L$

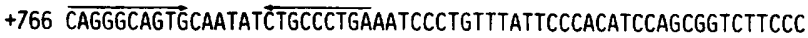
+826 GATC
\end{abstract}

Fig. 6. Nucleotide sequence of the phoC ORF and flanking regions. Number 1 represents the first base of the start codon of the phoC ORF. Putative sequences involved in transcriptional control, identified on the basis of similarity with $E$. coll consensus sequences, are underlined ( -10 regions) or overlined (-35 regions). Two convergent arrows indicate the downstream inverted repeat possibly functioning as a transcriptional terminator. The putative ribosomal-binding site is boxed. The deduced amino acid sequence of the PhoC protein is reported under the nucleotide sequence. The signal sequence of the PhoC protein is underlined.

for a polypeptide of 249 amino acids with a predicted molecular mass of $27002 \mathrm{Da}$. The deduced amino acid sequence of the amino-terminal region of the polypeptide showed features resembling those of procaryotic signal sequences for protein export to the periplasmic space (Oliver, 1985) and, on the basis of amino-terminal sequencing data, it actually appeared to function as a signal sequence which is cleaved by signal peptidase after the alanine residue at position 20 . A putative ribosomalbinding site resembling those of $E$. coli is located just upstream of the ATG codon. The phoC ORF is preceded by putative promoter sequences, and a $9 \mathrm{bp}$ inverted repeat, which could function as a tho-independent transcription terminator, is located downstream of the ORF (Fig. 6).
All E. coli strains harbouring recombinant plasmids which included the $p h o C$ ORF and flanking sequences showed strong $p$ NPP hydrolysing activity and were able to produce the PhoC protein, independently of the insert orientation and of the presence of $E$. coli promoter sequences located near the insert junctions. On the other hand, strains harbouring recombinant plasmids which contained only a portion of the phoC ORF, obtained by deletion of the inset of plasmid pPM12R using exonuclease III and nuclease $\mathrm{S} 1$, showed a $p \mathrm{NPP}$ hydrolysing activity comparable to that of E. coli DH5 $\alpha$ (pBluescript) and were no longer able to produce the $25 \mathrm{kDa}$ polypeptide (Fig. 4). These data were in agreement with the hypothesis that the above ORF actually encoded the PhoC protein, and also suggested that the Morganella DNA sequences located upstream of the $p h o C$ gene could promote transcription of the same gene in E. coli.

The $\mathrm{G}+\mathrm{C}$ contents of the sequenced region $(47 \%)$ and of the phoC ORF (52\%), as well as at the third position of codons $(54 \%)$, are consistent with the value reported $(50 \%)$ for the M. morganii genome (Falkow et al., 1962).

\section{Comparison of the primary structure of the Morganella PhoC enzyme to that of other bacterial acid phosphatases}

The deduced amino acid sequence of the $M$. morganii PhoC enzyme was compared to all protein sequences present in the SwissProt database (release 24.0) by means of the FASTA program (Pearson, 1990). A significant degree of sequence homology was found between this enzyme and three other bacterial acid phosphatases, i.e. the PhoC principal acid phosphatase of Zymomonas mobilis (Pond et al., 1989), the PhoN nonspecific acid phosphatase of S. typhimurium (Groisman et al., 1992; Kasahara et al., 1991) and the PhoN acid phosphatase of P. stuartii (M. L. Riccio, G. Lombardi, A. Chiesurin \& G. Satta, unpublished results; EMBL accession number X64820). The result of multiple sequence alignment analysis within this family of enzymes, which we propose to indicate as class A bacterial acid phosphatases, showed the existence of several conserved regions shared by the four proteins, including two cysteine residues and a perfectly conserved 8-amino-acid sequence, GSYPSGHT (Fig. 7). At the sequence level, the enzymes from $M$. morganii and $P$. stuartii are more similar to each other than to the other two proteins. Considering the 201-amino-acid region that could be aligned virtually without gaps in all sequences (corresponding to amino acids 44-244 of the Morganella enzyme; see Fig. 7), the overall amino acid identity was $84.6 \%, 45.3 \%$, and $37.8 \%$ when the $M$. morganii $\mathrm{PhoC}$ enzyme was aligned with the $P$. stuartii, $S$. typhimurium, and $Z$. mobilis enzymes, respectively, while the degree of similarity increased to $94.4 \%, 80.6 \%$ and $77 \cdot 1 \%$, respectively, after allowing for conservative amino acid substitutions. The homology among the same regions at the nucleotide sequence level was $71.8 \%, 52 \cdot 1 \%$, and $46.9 \%$ when the Morganella phoC sequence was compared to the $P$. stuartii, S. typhimurium, and $Z$. mobilis sequences, respectively. 


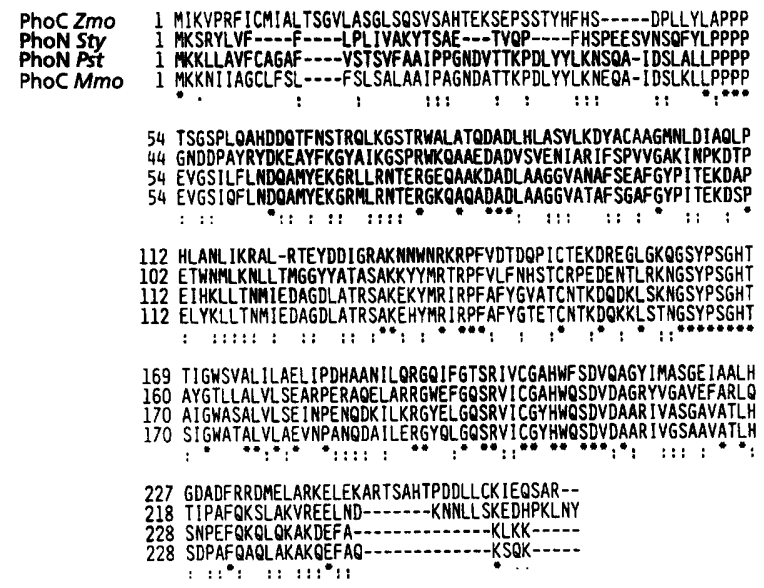

Fig. 7. Comparison of the deduced amino acid sequence of the PhoC phosphatase of $M$. morganii RS12 (PhoC Mmo) with those of the PhoC phosphatase of Z. mobilis CP4 (PhoC Zmo) (Pond et al., 1989), the PhoN phosphatase of S. typhimurium ATCC 14028 (PhoN Sty) (Groisman et al., 1992), and the PhoN phosphatase of P. stuartii PV81 (PhoN Pst) (M. L. Riccio, G. Lombardi, A. Chiesurin \& G. Satta, unpublished results; EMBL accession number $\mathrm{X64820}$ ). Numbers located at the left correspond to the residue numbers of the respective proteins. Identical residues are indicated by an asterisk; conservative amino acid substitutions are indicated by a colon.

The high level of homology between the M. morganii and the $P$. stuartii class $\mathrm{A}$ acid phosphatases at the nucleotide sequence level is consistent with previous results, which showed that a probe made from a fragment of the $P$. stuartii pho $N$ gene was able to hybridize with $M$. morganii genomic DNA under low stringency conditions (Thaller et al., 1992b). On the basis of these data it could be speculated that also in $P$. stuartii, which is the other $\mathrm{HPAP}^{+}$enterobacterial species thus far described, this phenotype is associated with a phosphate-irrepressible production of the respective class A phosphatase.

\section{Vertical phylogeny versus horizontal transfer of class $A$ acid phosphatases in enteric bacteria}

From studying base composition and codon usage data, and the presence of a nucleotide sequence showing similarity to the oriT region of incFII plasmids and located upstream of the gene, it has recently been suggested that the phoN gene of $S$. typhimurium was acquired by lateral transmission from another species with a low $\mathrm{G}+\mathrm{C}$ genomic content in a plasmid-mediated event (Groisman et al., 1992). This is apparently not the case for the $M$. morganii phoC gene. In fact, the occurrence of highly homologous class A acid phosphatase genes in more than one member (M. morganii and $P$. stuartii) of the enterocluster 3 lineage (Ahmad et al., 1990), along with the fact that the $G+C$ contents of the above genes (also at the third position of the codons) is consistent with the overall $\mathrm{G}+\mathrm{C}$ contents of the respective species (Falkow et al., 1962), suggest that these genes are vertically derived from a common ancestor present in the corresponding lineage before divergence of the above species. Moreover, considering the sequence data, it appears unlikely that the $S$. typhimurium pho $N$ gene has been derived by lateral transfer from $M$. morganii or $P$. stuartii. In fact, of the two latter species, only $P$. stuartii, which has a low $G+C$ content both at the genomic level $(41 \%$ versus $50 \%$ of Morganella; Falkow et al., 1962) and in its own phoN gene ( $43 \%$ versus $52 \%$ of the Morganella pho $C$ gene), could be a suitable donor candidate, given the low $\mathrm{G}+\mathrm{C}$ content of the Salmonella phoN gene (Groisman et al., 1992). In this case, however, a significantly higher degree of similarity with the Salmonella gene would have been expected for the $P$. stuartii gene than for the $M$. morganii gene, and an overall higher degree of similarity would have also been expected between the Salmonella gene and the genes of the two enterocluster 3 members.

Unlike the PhoN enzyme of $S$. typhimurium, the production of which is regulated by several environmental conditions and is moderately induced by $\mathrm{P}_{i}$ starvation (Kier et al., 1977b), the $M$. morganii class $A$ acid phosphatase is produced in a $\mathrm{P}_{1}$-irrepressible fashion and $P_{i}$ starvation actually seemed to somewhat repress its production while inducing alkaline phosphatase. The production of class A acid phosphatases, therefore, appears to be under the control of different regulatory systems in these two enterobacterial species, and this is consistent with a different evolutionary history of these genes.

We are currently investigating the presence of homologous genes in other bacterial species to ascertain the intriguing evolutionary history of this gene family.

\section{Concluding remarks}

Results of this study indicate that the set of phosphatases of $M$. morganii is different from both that of E. coli and that of $S$. typhimurium, while sharing with them some common features. Morganella, in fact, is able to produce both an alkaline phosphatase (similarly to $E$. coli and unlike Salmonella) and a class A nonspecific acid phosphatase (similarly to Salmonella and unlike E. coli). Regulation of the former enzyme is apparently similar to that of E. coli, while the class $A$ acid phosphatase is apparently regulated in a different way as compared to the $S$. typhimurium homologue. These findings therefore support the hypothesis that different sets of phosphatases have evolved in Enterobacteriaceae.

The role of class A acid phosphatases in microbial physiology, as well as the significance of their different regulation in different species, remains to be determined. In members of the genus Salmonella this gene appears to be widespread, but strains are found which are no longer able to produce the PhoN protein owing to recent mutational events (Groisman et al., 1992). PhoN production is apparently dispensable under laboratory conditions (Uerkvitz \& Beck, 1981), and is also not important for microbial pathogenicity notwithstanding the recruitment of the $p h o N$ gene under the $p h o P-p h o Q$ virulence regulon (Fields et al., 1989; Miller et al., 1989). A similar situation is consistent with the evolutionary origin of the $p h o N$ gene which has been acquired by horizontal transfer 
(Groisman et al., 1992). Since in Morganella the evolutionary history of the $p h o C$ gene and its regulation are apparently different from those of the homologous Salmonella pho $N$ gene, it would be of interest to understand the role of the PhoC enzyme and its high-level production in this species.

\section{ACKNOWLEDGEMENTS}

This work was supported in part by grant nos 92.01253. PF70 and 92.01195. PF70 from the Italian National Research Council (C.N.R.), targeted project 'Biotecnologie e Biostrumentazione', and no. 92.02779.CT04 from the C.N.R. We should like to thank Giuseppe Satta for helpful suggestions and discussions, Annalisa Santucci for amino-terminal sequencing of the PhoC enzyme, and Maria Letizia Riccio, who works at the Department of Molecular Biology of the University of Siena, for sharing with us information on the plate functional assay used for library screening and on the nucleotide sequence of the $P$. stuartii pho $N$ gene. Thanks are also due to Francesco Lissi and Elena Sestini for their patient and skilful editorial assistance.

\section{REFERENCES}

Ahmad, S., Weisburg, W. G. \& Jensen, R. A. (1990). Evolution of aromatic amino acid biosynthesis and application to the fine-tuned phylogenetic positioning of enteric bacteria. $J$ Bacteriol 172, 1051-1061.

Ames, B. N. (1966). Assay of inorganic phosphate, total phosphate and phosphatases. Methods Enzymol 8, 115-118.

Bradshaw, R. A., Cancedda, F., Ericsson, L. H., Neuman, P. A., Piccoli, S. P., Schlesinger, M. J., Schrifer, K. \& Walsh, K. A. (1981). Amino acid sequence of Escherichia coli alkaline phosphatase. Proc Natl _Acad Sci US A 78, 3473-3477.

Cocks, G. T. \& Wilson, A.C. (1972). Enzyme evolution in the Enterobacteriaceae. J Bacteriol 110, 793-802.

Dassa, E., Cahu, M., Desjoyaux-Cherel, B. \& Boquet, P. L. (1982). The acid phosphatase with optimum $\mathrm{pH}$ of 2.5 of Escherichia coli: physiological and biochemical study. J Biol Chem 257, 6669-6676.

Dvorak, H. F., Brockman, R. W. \& Heppel, L. A. (1967). Purification and properties of two acid phosphatase fractions isolated from osmotic shock fluid of Escherichia coli. Biochemistry 6, 1743-1751.

Falkow, S., Ryman, I. R. \& Washington, O. (1962). Deoxyribonucleic acid base composition of Proteus and Providence organisms. J Bacteriol 83, 1318-1321.

Farmer, J. J. III \& Kelly, M. T. (1991). Enterobacteriaceae. In Manual of Clinical Microbiology, 5th edn, pp. 360-383. Edited by A. Balows, W. J. Hausler Jr, K. L. Herrmann, H. D. Isenberg \& H. J. Shadomy. Washington DC: American Society for Microbiology.

Ferro-Luzzi Ames, G., Prody, C. \& Kustu, S. (1984). Simple, rapid, and quantitative release of periplasmic proteins by chloroform. $J$ Bacteriol 160, 1181-1183.

Fields, P. I., Groisman, E. A. \& Heffron, F. (1989). A Salmonella locus that controls resistance to microbicidal proteins from phagocytic cells. Science 243, 1059-1062.

Frankel, G., Newton, S. M. C., Schoolnik, G. K. \& Stocker, B. A. D. (1989). Unique sequences in the region VI of the flagellin gene of Salmonella typhi. Mol Microbiol 3, 1379-1383.

Garen, A. \& Levinthal, C. (1960). A fine-structure genetic and biochemical study of the enzyme alkaline phosphatase of $E$. coli. Biochim Biophys Acta 38, 470-483.

Groisman, E. A., Saier, M. H. Jr \& Ochman, H. (1992). Horizontal transfer of a phosphatase gene as evidence for mosaic structure of the Salmonella genome. EMBO J 11, 1309-1316.

Hawkey, P. M., Penner, J. L., Linton, A. H., Hawkey, C. A., Crisp, L. J. \& Hinton, M. (1986). Speciation, serotyping, antimicrobial susceptibility and plasmid content of Proteeae from the environment of calf-rearing units in south west England. J Hyg 97, 405-417.

Henikoff, S. (1984). Unidirectional digestion with exonuclease III creates targeted breakpoints for DNA sequencing. Gene 28, 351-359.

Higgins, D. G. \& Sharp, P. M. (1988). Clustal: a package for performing multiple sequence alignment on a microcomputer. Gene 73, 237-244.

Kasahara, M., Nakata, A. \& Shinagawa, H. (1991). Molecular analysis of the Salmonella typhimurium pho $N$ gene, which encodes nonspecific acid phosphatase. J Bacteriol 173, 6770-6775.

Kier, L. D., Weppelman, R. \& Ames, B. N. (1977a). Resolution and purification of three periplasmic phosphatases of Salmonella typhimurium. J Bacteriol 130, 399-410.

Kier, L. D., Weppelman, R. \& Ames, B. N. (1977b). Regulation of two phosphatases and a cyclic phosphodiesterase of Salmonella typhimurium. J Bacteriol 130, 420-428.

Laemmli, U. K. (1970). Cleavage of structural proteins during the assembly of the head of bacteriophage T4. Nature 227, 680-685.

Lis, J. T. (1980). Fractionation of DNA fragments by polyethylene glycol induced precipitation. Methods Enzymol 65, 347-353.

Matsudaira, P. (1987). Sequence from picomole quantities of proteins electroblotted onto polyvinylidene difluoride membranes. $J$ Biol Chem 262, 10035-10038.

Miller, S. I., Kukral, A. M. \& Mekalanos, J. J. (1989). A twocomponent regulatory system ( $p h o P$ phoQ) controls Salmonella typhimurium virulence. Proc Natl Acad S $i$ US A 86, 5054-5058.

Neu, H. C. (1968). The $5^{\prime}$-nucleotidases and cyclic phosphodiesterases ( 3 '-nucleotidases) of the Enterobacteriaceae.J Bacteriol 95, $1732-1737$.

Oliver, D. (1985). Protein secretion in Escherichia coli. Annu Rev Microbiol 39, 615-618.

Pearson, W. R. (1990). Rapid and sensitive sequence comparison with FASTP and Fasta. Metbods Enzymol 183, 63-98.

Phillips, J. E. (1955). In vitro studies of Proteus organisms of animal origin. J Hyg 53, 26-31.

Pompei, R., Cornaglia, G., Ingianni, A. \& Satta, G. (1990). Use of a novel phosphatase test for simplified identification of species of the tribe Proteae. J Clin Microbiol 28, 1214-1218.

Pompei, R., Ingianni, A., Foddis, G., Di Pietro, G. \& Satta, G. (1993). Patterns of phosphatase activity among enterobacterial species. Int J Syst Bacteriol 43, 174-178.

Pond, J. L., Eddy, C. K., Mackenzie, K. F., Conway, T., Borecky, D. J. \& Ingram, L. O. (1989). Cloning, sequencing, and characterization of the principal acid phosphatase, the $p h o C^{+}$product, from Zymomonas mobilis. J Bacteriol 171, 767-774.

Reiland, J. (1971). Gel filtration. Methods Enzymol 22, 287-321.

Sambrook, J., Fritsch, E. F. \& Maniatis, T. (1989). Molecular Cloning: a Laboratory Manual, 2nd edn. Cold Spring Harbor, NY: Cold Spring Harbor Laboratory.

Sanger, F., Nicklen, S. \& Coulson, A. R. (1977). DNA sequencing with chain-terminating inhibitors. Proc Natl Acad Sci USA 74, 5463-5467.

Satta, G., Grazi, G., Varaldo, P. E. \& Fontana, R. (1979). Detection of bacterial phosphatase activity by means of an original and simple test. J Clin Pathol 32, 391-395. 
Satta, G., Pompei, R., Grazi, G. \& Cornaglia, G. (1988). Phosphatase activity is a constant feature of all isolates of all major species of the family Enterobacteriaceae. J Clin Microbiol 26, 2637-2641.

Schlesinger, M. J. \& Olsen, R. (1968). Expression and localization of Escherichia coli alkaline phosphatase synthesized in Salmonella typbimurium cytoplasm. J Bacteriol 96, 1601-1605.

Thaller, M. C., Berlutti, F., Pantanella, F., Pompei, R. \& Satta, G. (1992a). Modified MacConkey medium which allows simple and reliable identification of Providencia stuartii. $J$ Clin Microbiol 30 , 2054-2057.

Thaller, M. C., Berlutti, F., Riccio, M. L. \& Rossolini, G. M. (1992b). A species specific DNA probe for Providencia stuartii identification. Mol Cell Probes 6, 417-422.

Torriani, A. (1960). Influence of inorganic phosphate in the formation of phosphatases by Escherichia coli. Biochim Biophys Acta 38, 460-469.

Uerkvitz, W. \& Beck, C. F. (1981). Periplasmic phosphatases in Salmonella typhimurium LT2. A biochemical, physiological, and partial genetic analysis of three nucleoside monophosphate dephosphorylating enzymes. $J$ Biol Chem 256, 382-389.

Von Graevenitz, A. \& Spector, H. (1969). Observations on indole positive Proteus. Yale J Biol Med 41, 434-445.

Weppelman, R., Kier, L. D. \& Ames, B. N. (1977). Properties of two phosphatases and a cyclic phosphodiesterase of Salmonella typhimurium. J Bacteriol 130, 411-419.

Williams, E. W., Hawkey, P. M., Penner, J. L., Senior, B. W. \& Barton, L. (1983). Serious nosocomial infections caused by Morganella morganii and Proteus mirabilis in a cardiac surgery unit. $J$ Clin Microbiol 18, 5-9.

Winslow, C.-E. A., Kliger, I. J. \& Rothberg, W. (1919). Studies on the classification of the colon-typhoid group of bacteria with special reference to their reactions. J Bacteriol 4, 429-503.

Received 16 September 1993; revised 8 December 1993; accepted 5 January 1994. 